\title{
Fontis nympha sacri. Deidades del agua en el arte y en la literatura francesa
}

\author{
Gonzalo-Santos, Tomás
}

Universidad de Salamanca, tgonzalo@usal.es

\begin{abstract}
Resumen
La leyenda Fontis nympha sacri somnum ne rumpe quiesco figura en las variaciones que sobre el motivo de las ninfas pintara Lucas Cranach el Viejo en el segundo cuarto del siglo XVI. El texto en latín ilustra a la perfección una de las escenas más repetidas de cuantas atañen a estas deidades del agua: la ninfa de la fuente o la ninfa dormida. En efecto, los pintores y grabadores del Renacimiento recrearon una y otra vez esta escena inspirándose en la mitología, la coartada cultural necesaria para llevar temas eróticos al arte. A partir de estas imágenes, comenzaron a proliferar distintas recreaciones literarias, muy cercanas en un principio a las representaciones icónicas. Nos detendremos aquí en algunos escritores franceses que, desde el siglo XVII hasta el XX, aportaron su contribución al motivo de la ninfa dormida o la ninfa en el baño; principalmente en los diferentes subgéneros novelescos que fueron sucediéndose en el favor del público: novela pastoril o heroica, sentimental o campestre. Autores como Honoré d'Urfé, La Calprenède, La Fontaine, Marivaux, George Sand, Marguerite Yourcenar e incluso Marcel Pagnol van reelaborando la escena y se apartan con ello, paulatinamente, del tratamiento inicial, lo que supone perder -al menos aparentemente- toda referencia mitológica.
\end{abstract}

Palabras clave: ninfas; mitología; género pastoril; pintura y literatura.

\section{Résumé}

La légende Fontis nympha sacri somnum ne rumpe quiesco apparaît dans les variations peintes par Lucas Cranach le Vieux sur le motif des nymphes dans le deuxième quart du XVIe siècle. Le texte en latin illustre à la perfection l'une des scènes les plus répétées parmi celles qui concernent les déités de l'eau: la nymphe de la source ou la nymphe endormie. En effet, les peintres et les graveurs de la Renaissance ont recréé à plusieurs reprises cette scène s'inspirant de la mythologie, l'alibi culturel nécessaire pour transposer des sujets érotiques dans l'art. À partir de ces images, on a vu proliférer différentes recréations littéraires, très proches à l'origine des représentations iconiques. Nous nous arrêterons ici sur quelques écrivains français qui, du XVIIe jusqu'au XXe siècle, ont apporté leur contribution au motif de la nymphe endormie ou de la nymphe au bain; à commencer par les différents sous-genres romanesques qui se sont succédés dans la faveur du public: bergeries, roman héroïque, sentimental ou champêtre. Des auteurs tels qu'Honoré d'Urfé, La Calprenède, La Fontaine, Marivaux, George Sand, Marguerite Yourcenar et même Marcel Pagnol réélaborent la scène en s'écartant peu à peu du traitement initial, ce qui revient-apparemment au moins- à perdre toute référence mythologique.

Mots-clés: nymphes; mythologie; bergeries; peinture et littérature.

\begin{abstract}
The inscription Fontis nympha sacri somnum ne rumpe quiesco appears in the variations that Lucas Cranach the Old took on nymphs' motive in the second quarter of the fourteenth century. The text in Latin illustrates perfectly one of the most repeated scenes amongst those who concern such water deities: the nymph of the spring or the sleeping nymph. Indeed, Renaissance painters and engravers recreated once and again this scene drawing on mythology, the necessary cultural alibi to introduce erotic subjects in art. From these images, different literary recreations very close to iconic representations at the beginning, started to emerge. We will stop now in some French writers who, from the seventeenth century to the twentieth, made their contribution to the sleeping nymph or the bathing nymph motive; mainly in the different novelistic subgenres that have been undertaken in favour of the public: pastoral or heroic
\end{abstract}


romance, sentimental or rural novel. Authors like Honoré d'Urfé, La Calprenède, La Fontaine, Marivaux, George Sand, Marguerite Yourcenar and even Marcel Pagnol have been reworking the scene and this makes them progressively deviate from the initial treatment, which implies the loss of any mythological reference - at least apparently.

Keywords: nymphs; mythology; pastoral; painting and literature.

Entre las deidades del agua que proliferan en distintas leyendas y tradiciones (Molina Foix, 2005), me detendré en las que ofrece la mitología grecolatina y, en particular, en las ninfas. Ahora bien, los griegos distinguían perfectamente, dentro de ese término genérico, muchas categorías aunque no siempre bien sistematizadas (Larson, 2001: 359-364). Simplificando mucho, diremos que estaban, por un lado, las ninfas de los bosques: Dríades -que por ellos erraban libremente- y Hamadríades -asociadas a un solo árbol-; por otro, las ninfas acuáticas: las Náyades, de agua dulce, y las Oceánides; y, dentro de estas, las Nereidas. De las ninfas del agua trataré, ya que el agua nos ha traído hasta aquí, hasta esta ribera.

En primer lugar están, por lo tanto, las referencias mitológicas. Pero es muy probable que una de las primeras fuentes icónicas modernas venga de la obra alegórica El sueño de Polifilo ${ }^{1}$ impreso en Venecia en 1499, pues en ella se halla descrita una bella ninfa dormida y el texto va acompañado de una imagen que parece haber hecho escuela. Así, en la excelente versión francesa de 1546 y también en la reimpresión de $1554^{2}$, se encuentra un grabado -atribuido a Jean Goujon- que mejora en mucho el original gracias a las innovaciones técnicas que se producen en esos años.

En él queda fijada la postura de la durmiente que, con distintas variantes, se perpetuará en la pintura. De hecho, aunque muchos artistas recreen una y otra vez escenas de ninfas, estas se contaminarán muy pronto con imágenes de AfroditaVenus, o incluso de Artemisa-Diana, pero con ello no hacen sino seguir la estela marcada por los mitos, que se cruzan y superponen entre sí, o con otros próximos. Así, uno de los primeros y más bellos cuadros pintados sobre el tema, precisamente en Venecia, es el conocido como la Venus dormida de Giorgione que se ha datado hacia 1510 y se conserva en la Gemäldegalerie de Dresde. Tiziano seguirá sus pasos de cerca y hará de ella uno de los motivos principales de su arte, llevándola a escenas de interior, como la Venus de Urbino (Galería Uffizi, Florencia), y a lo alegórico.

Adormecidas, despiertas o simplemente recostadas, han de tomarse como recreaciones del motivo de las ninfas pues solo en ellas es propio quedarse dormidas en medio de la naturaleza, con frecuencia al lado de un caudal de agua, que no en vano son las deidades de esos lugares.

No es casual tampoco que sean rescatadas en el Renacimiento. El espíritu humanista que lo caracteriza trajo, junto a la recuperación de los clásicos y consiguientemente de la mitología, el desarrollo de una doctrina que marcará de manera indeleble el pensamiento y el arte-también la literatura-, en el siglo XVI y buena parte del XVII: el neoplatonismo, que hará de la búsqueda de la belleza uno de sus temas capitales. Este ideal es el que reproducen esas imágenes, que son más que un mero pretexto para disponer de escenas eróticas. Giorgione, que participó de esos círculos intelectuales, lo refleja perfectamente.

Desde el punto de vista estético, el canon de belleza femenina plasmado por Giorgione es el que parece haberse impuesto y no el de Lucas Cranach el Viejo, quien hizo de ellas prácticamente una especialidad. Cuando empecé esta búsqueda, hace ya muchos años y con muchos menos medios, pensaba que Cranach había pintado dos cuadros de ninfas dormidas, el de la National Gallery de Washington y el de la colección Thyssen-Bornemisza de Madrid. Ahora sé que se conocen al menos dieciséis versiones: o mucho le gustaba el tema o tenía mucha demanda, o ambas cosas a la vez. Y tuvo imitadores, empezando por su propio hijo, Lucas Cranach el Joven, con menos arte.

La leyenda «Fontis nympha sacri somnum ne rumpe quiesco» figura en las distintas variaciones que sobre el motivo de las ninfas pintara Cranach el Viejo en el segundo cuarto del siglo XVI (Ruiz de Elvira, 1999: 177-180). El texto en latín -que podríamos traducir como «[Soy] la ninfa de la fuente sagrada, no interrumpas mi sueño: descanso»- ilustra a la

\footnotetext{
${ }^{1}$ Considerada la primera obra de arte de la tipografía y atribuida a Francesco Colonna, salió del taller de uno de los impresores más famosos de todos los tiempos, Aldo Manuzio.
}

${ }^{2}$ Hypnerotomachie ou Discours du songe de Poliphile (f.23). Paris, Jacques Kerver, 1554. 
perfección una de las escenas más repetidas de cuantas atañen a estas deidades del agua: la ninfa de la fuente o la ninfa dormida. Cabe preguntarse, con Goyet (2012), si es una verdadera ninfa o una dama que juega a serlo, pues en alguna de las versiones -como la Ninfa de la fuente de la National Gallery- lleva alhajas y hay un palacio en las proximidades. Además, la presencia, común a todas, del arco y la aljaba induce a confusión por asociarse estos a Diana cazadora y a las ninfas que la acompañan, que son dríades y no acuáticas; claro que podrían relacionarse también con Cupido.

En todo caso, la inclusión de las dos tórtolas en el cuadro es significativa por cuanto simbolizan la fidelidad: creo que remiten a ese ideal de belleza y amor que es la razón de ser del neoplatonismo. Máxime si se considera que del taller de Lucas Cranach salieron también dos cuadros, por lo menos, con el tema de La Edad de Oro (Galería Nacional de Oslo y Alte Pinakothek de Múnich). Esta utopía -conocida también como el siglo de la diosa Astrea, una era cíclica de justicia y paz- resurgió con fuerza en el Renacimiento y será reivindicada una y otra vez por los libros de pastores, en los que la doctrina amorosa mencionada ocupa un lugar preponderante. Bien se puede deducir que los artistas de esa época estaban al tanto del marco teórico en el que se inscribían sus representaciones.

Lo cierto es que, conforme pasen los años y los estilos pictóricos, la ninfa, que inicialmente se había metamorfoseado en Venus, se transformará en odalisca o cortesana y acabará no solo despierta, sino mirando descaradamente al espectador; y, una vez liberado el arte de sus ataduras morales, en simples desnudos femeninos, lo que los hace progresivamente más provocativos, desprovistos ya del pretexto mitológico. Sorprende, no obstante, descubrir hasta qué punto muchos de ellos se atienen a la postura consagrada desde un principio, dando lugar a un juego de hipericonicidad de los más palmarios en las artes plásticas: desde un Tiziano (La bacanal de los Andrios, 1523-1526, Museo del Prado) a un Poussin afincado en Italia que multiplicó este tipo de imágenes y fue objeto de innumerables copias ${ }^{3}$. Ingres es, no obstante, el artista perfecto para ilustrar las sucesivas versiones de este motivo ${ }^{4}$, que va a actualizar homenajeando a artistas anteriores como Poussin, quien había tomado a su vez el tema y el tratamiento mismo de Tiziano.

La tradición reza que, si no hay sátiro en el cuadro, el sátiro es uno y, si lo hay, también, pero convertido doblemente en voyeur. En la versión de Ingres de 1851, Ninfa y sátiro (Museo de Orsay), reaparece este personaje inquietante, que ya figuraba en el grabado del Sueño de Polifilo. Con él se rompe el equilibrio que irradian las ninfas dormidas, pues trae consigo -aunque sea de manera latente- toda la violencia del instinto sexual (Lavocat, 2005). Entre el sinfín de cuadros que se han dedicado a tal asunto, destacan Venus y Amor sorprendidos por un sátiro, de Correggio (1524-1525), y Ninfa y sátiro, de Antoine Watteau; ambos en el Museo del Louvre y ambos conocidos durante mucho tiempo -al igual que el de Ingres- como Júpiter y Antíope. Buena prueba de la dificultad que entraña identificar el motivo exacto; dificultad que deriva de la doble hibridación: la que llevan inscrita los mitos y la propia de la pintura.

¿Qué hacen entretanto los escritores a partir de estos precedentes mitológicos y pictóricos?

Analizaré aquí a algunos franceses que, desde el siglo XVII hasta el XX, aportaron su contribución al topos de la ninfa dormida o de las ninfas en el baño; principalmente en los distintos subgéneros novelescos que fueron sucediéndose en el favor del público: novela pastoril, heroica, sentimental o campestre (Gonzalo Santos, 1986: 149-156). Autores como Honoré d’Urfé, La Calprenède, La Fontaine, Marivaux, George Sand, Marguerite Yourcenar o incluso Marcel Pagnol van reelaborando la escena y se apartan con ello, paulatinamente, del tratamiento inicial, lo que supone perder -al menos aparentemente- toda referencia mitológica.

Honoré d’Urfé es el primero, entre los franceses, en servirse de manera sistemática del juego que estas escenas proporcionaban para atraer la atención de los lectores, poniendo pastoras donde antes había ninfas. Y lo hace en su magna obra, L'Astrée, de la que se publicaron tres gruesos volúmenes en vida del autor, entre 1607 y 1619, y dos más tras su muerte ${ }^{5}$. D’Urfé mantiene la postura canónica de la ninfa dormida y aunque la viste, por razones de decoro, conserva una cierta desnudez y la visión furtiva de la misma, que acrecientan su carga erótica; no en vano representan, respectivamente, los dos componentes básicos del erotismo, en palabras de George Bataille (1957: 40), lo prohibido y la transgresión:

\footnotetext{
${ }^{3}$ Ninfa dormida. Dibujo a partir de Nicolas Poussin. Escuela francesa. INV 32549, recto. Museo del Louvre, Fondo de dibujos y miniaturas.

${ }^{4}$ Como la Odalisca con esclava (1839-1840). Harvard University Museums, Cambridge, Massachusetts.

${ }^{5}$ Las ediciones conjuntas de L'Astrée constan pues de cinco partes. Cada una de ellas va dividida en doce libros y, en las referencias a los ejemplares que manejamos, unas y otros van en caracteres romanos: aquellas, en normales y estos, en versalitas. Esta edición moderna incluye las ilustraciones de 1632-1633 y 1733.
} 
Elle avoit un mouchoir dessus les yeux qui luy cachoit une partie du visage, un bras sous la teste et l'autre estendu le long de la cuisse, et le cotillon, un peu par mesgarde, ne cachoiy pas entierement la beauté de la jambe. Et d'autant que son corps de jupe la serroit un peu, elle s'estoit deslassée, et n'avoit rien sur le sein qu'un mouchoir de reseul au travers duquel la blancheur de sa gorge paroissoit merveilleusement... (Urfé: II, vIII, 329-333).

En realidad, antes de llegar a pintar ese cuadro exquisito, d’Urfé ya se había iniciado en el género con varios esbozos: uno en la Primera Parte, donde Astrée finge hallarse dormida para ser besada por Céladon (I, IV, 118-120); otro de la pastora Diana, atacada mientras duerme por un bárbaro extranjero (I, VI, 226-235) -léase sátiro-; y uno de los cuadros de que se compone la secuencia pictórica de Damon y Fortune, donde retrata a esta pastora dormida (I, XI, 451). No contento con esto, retomará el tema al menos en otra ocasión llevándolo a una escena de interior: en la Tercera Parte, Astrée es sorprendida en el lecho por un Céladon, travestido de mujer (III, X, 549-552). Incluso invertirá los papeles, haciendo que sean las ninfas las que sorprendan al pastor dormido; y los ilustradores dieron buena cuenta de ello en las ediciones de L'Astrée de 1632-1633 y 1733. Además, d’Urfé creó escuela: Jean Mairet introduce el tema de la durmiente en su tragicomedia pastoril, La Silvanire ou La morte-vive, lo que supone llevarlo a la escena; y el mismo grabador de L'Astrée de 1632, Michel Lasne, tuvo a bien dedicarle una de las láminas en la edición impresa (Marsan, 1969: Apéndice).

En un ejercicio más de intertextualidad, La Calprenède copia fielmente la escena en su novela Cassandre (1645), deudora de L'Astrée pero en registro heroico, colocando -según el gusto del momento-princesas donde había encontrado pastoras: «La Princesse avait la tête appuyée sur sa main, l'autre bras découvert jusqu’au coude était négligemment étendu sur sa cuisse, sa gorge alors dans la perfection n'était cachée qu’à moitié par un voile d'une gaze légère» (1752: I, 153). Y debió complacerse en ella pues la repitió con menos gracia en Faramond (1753: II, 10-11).

La Fontaine, que era otro erotómano avant la lettre -como el propio d'Urfé-, se deleitaba también en estas escenas que entresacaba y coleccionaba de sus lecturas preferidas, y desgrana en su Ballade des livres d'amour; ya fueran estas el Orlando furioso de Ariosto: «Et même quelquefois j'entre en tentation / Lorsque l'ermite trouve Angélique endormie, / Rêvant à tel fatras souvent le long du jour ${ }^{6}$ ", o $L^{\prime}$ Astrée, de la que se declaraba devoto ${ }^{7}$ y a la que remiten estos versos de la Ode pour la Paix: «Fais qu'avecque le berger / On puisse voir la bergère, / Qui court d’un pied léger, /Qui danse sur la fougère // Et qui du berger tremblant / Voyant le peu de courage/ S'endorme ou fasse semblant / De s'endormir à l'ombrage». El fabulista no se engaña: esas pastoras -antes ninfas- no siempre están dormidas; bien se puede sospechar que solo lo fingen, lo que aviva el deseo y el sueño simulado pasa a formar parte de un juego erótico de seducción (Leroux, 2011: 15-35).

Y, al pasar de la lectura a la escritura, se las arregla para introducir su escena favorita. Primero, en Les Amours de Psyché et Cupidon (La Fontaine, 1965: 450-451) que data de 1669. Luego, en la ensoñación poética, a medio camino entre prosa y verso, Le Songe de Vaux, publicada póstumamente y deudora por cierto del Sueño de Polifilo:

Cette belle Nymphe était couchée sur des plantes de violettes, sa tête à demi penchée sur un de ses bras, et l'autre étendu le long de sa jupe. Ses manches, qui s'étaient un peu retroussées par la situation que le sommeil lui avait fait prendre, me découvraient à moitié ces bras si polis. Je ne sus à laquelle de leurs beautés donner l'avantage, à leur forme ou à leur blancheur, bien que cette dernière fît honte à l'albâtre. [..] Je n'entreprendrai de décrire ni la blancheur ni les autres merveilles de ce beau sein, ni l'admirable proportion de la gorge, qu'il était aisé de remarquer malgré le linomple, et qu'une respiration douce contraignait parfois de s'enfler(La Fontaine, 1967: 189-192).

Marivaux recoge en sus novelas de juventud el motivo en cuestión, que convierte en escena de amor a primera vista a los ojos de Frédélingue, el protagonista masculino de Les Effets surprenants de la sympathie, de nítidas resonancias neoplatónicas: «ll vit la plus aimable femme qu’on puisse voir, couchée sur un lit de repos semé de fleurs. Cette personne était endormie; la manière dont elle était couchée se joignant à sa beauté naturelle la rendait encore plus touchante; elle

\footnotetext{
${ }^{6}$ Véase el cuadro de Rubens, Angélica y el ermitaño (1626-1628). Kunsthistorisches Museum, Viena.

${ }^{7}$ Como bien recoge de nuevo la Ballade des livres d’amour «Non que monsieur d’Urfé n’ait fait une oeuvre exquise. / Étant petit garçon je lisais son roman, / Et je le lis encore ayant la barbe grise».
} 
était penchée; elle soutenait sa tête d'une de ses mains, et laissait voir le plus beau bras du monde...» (Marivaux, 1972a: 116-118). Y volverá sobre el asunto en Pharsamon ou les Nouvelles Folies romanesques -publicado en 1737 pero compuesto, como el anterior, entre 1712 y 1713-, haciendo del entorno un jardín, en lugar de la naturaleza abierta, y de la doncella una lectora soñadora, variante muy común a partir del siglo XVIII (Marivaux, 1972b: 396-403).

George Sand, apasionada por el arte y amante de la novela pastoril de la que se decía especialista, relaciona en los prefacios de sus novelas campestres ambos géneros (Gonzalo Santos, 1987: 103-113). En su primera tentativa, Jeanne de 1844, representa a su protagonista, una cabrera, sorprendida por tres jóvenes mientras duerme al aire libre, retomando así un tema muy querido de sus lecturas:

\begin{abstract}
Puis, sans ouvrir les yeux, elle prit à son insu une pose incroyablement gracieuse. Son bras était rejeté au-dessus de sa tête, et sa main brune, mais effilée et petite, rejeta en arrière sa coiffe de toile grise, et resta entr'ouverte sur ses cheveux d'un blond cendré magnifique. C’était bien le plus frais visage humain qui eût jamais bravé sans voile et sans ombrelle les ardeurs du soleil de midi [...] La dormeuse était donc blanche comme l’aster des prés et rosée comme la fleur de l'églantier. [...] Les lignes les plus pures et un calme angélique dans la physionomie lui donnaient une ressemblance frappante avec ces beaux types que l'art grec a immortalisés [...]; elle était vêtue de haillons qui, dans leur désordre pittoresque, ne la déparaient nullement (Sand, 1978: 41).
\end{abstract}

La imagen es, naturalmente, mucho más recatada que la de sus modelos pero guarda, en esencia, los rasgos fundamentales, que se mantendrán en el grabado para la célebre colección Hetzel (Sand, 1978). Además, la autora va a recrear la escena al final de la novela, añadiendo a la primera infracción la premonición sutil de una muerte inminente: «[sir Arthur] découvrit Jeanne abritée contre une grosse roche, et profondément endormie. Cette apparence de langueur et de paresse était bien contraire aux habitudes de Jeanne, et à ce préjugé rustique qu’il est dangereux de s’endormir aux champs. [...] Sa quenouille était encore attachée à son côté; son fuseau avait roulé à terre, et le fil était rompu» (Sand, 1978: 187).

Y luego están las ninfas raptoras de quienes osan acercarse a sus dominios, especialmente ríos y fuentes, a determinadas horas del día. Se podría afirmar que la mejor ilustración dentro de la mitología se encuentra en la historia del joven y agraciado Hilas, argonauta a la fuerza y arrebatado hacia las aguas por las náyades, que lo hacen inmortal. Ya fue muy celebrado en la antigüedad (Teócrito, 1986: 35-54) y el arte lo ha repetido hasta la saciedad: desde los mosaicos romanos (como el de Quintana del Marco, Museo Arqueológico Provincial de León), donde queda fijada también la postura canónica del héroe a su pesar (Regueras Grande, 1994: 33-37); a la pintura moderna, como Hilas y la Ninfa de François Gérard (Musée d'Art et d'Histoire Baron Gérard, Bayeux); o a la escultura, como la múltiples recreaciones de Hilas y las ninfas de las aguas por Bertel Thorvaldsen (MuseoThorvaldsen, Copenhague.).

En la literatura, una de las mejores recreaciones, por lo elaborada, está en L'Astrée, en el comienzo in medias res precisamente (Urfé, 1966: I, I, 13-17). En él tres ninfas -de nombre solamente, pues son damas de alcurnia- salvan oportunamente a Céladon, el protagonista, de su ahogamiento en el río Lignon ${ }^{8}$. Aparentemente, la escena mítica ha sido trastocada, pero no hay tal si tenemos en cuenta que las ninfas, atraídas por la belleza del jovencísimo pastor, lo mantienen en un dulce encierro y lo quieren para sí (Gonzalo Santos, 1991: 365-373).

No cabe extrañarse de la pervivencia del mito pues, según supersticiones vigentes en la Grecia rural de 1930 -en palabras de Marguerite Yourcenar (1982: 148), que le dedicó el relato L'Homme qui a aimé les Néréides-, contemplar la belleza de las ninfas a determinadas horas podía provocar la desaparición del voyeur o acarrearle la locura. Esto último es lo que le ocurre al pastor griego de la historia, que enloqueció tras su encuentro con unas supuestas ninfas: «Ce Panégyotis (il s’appelle ainsi) est devenu muet à dix-huit ans pour avoir rencontré les Néréides nues»(Yourcenar, 1982: 80-81):

A pesar de la actualización que imprime Yourcenar a su relato de 1938, da sobradas muestras de no haber perdido la filiación con el mito de base: al igual que Hilas y Céladon optaban a una condición superior en brazos de las ninfas, Panégyotis habría hecho otro tanto en los de sus nereidas, que bien podrían resultar... turistas americanas: «Les Nymphes

\footnotetext{
${ }^{8}$ Las ediciones ilustradas de 1632-1633 y 1733 reprodujeron fielmente el salvamento de Céladon en sendas láminas (Urfé, 1966: I, I).
} 
l'ont abêti pour mieux le mêler à leurs jeux, comme une espèce de faune innocent [...] Il est sorti du monde des faits pour entrer dans celui des illusions» (1982: 86-87).

Vayamos a Marcel Pagnol. Este había dirigido ya en 1953 un film sobre su Provenza natal con el título revelador de Manon des sources. Algunos años más tarde, en 1960, volverá sobre el tema con una novela, L'Eau des collines, que consta de dos partes: Jean de Florette y Manon des sources, y amplía en papel lo realizado en el cine. Pagnol conjuga aquí el drama rural y los temas de honda raigambre mitológica, en la estela de George Sand y sus novelas campestres. Y el texto tendrá su reflejo icónico, pero no será ya pictórico, sino fílmico: además de la incursión previa de Pagnol, Claude Berri pondrá en imágenes la novela de Pagnol en su díptico cinematográfico de 1986, y Manon presenta en él los rasgos de Emmanuelle Béart.

El personaje de Manon remite, como he señalado en otro lugar (Gonzalo Santos, 2014: 121-128), al mito de las ninfas. $\mathrm{Al}$ igual que estas, resulta ser una deidad del agua desde un principio y así se muestra a la jovencísima cabrera bañándose desnuda mientras es espiada por el campesino Ugolin -que hace aquí de sátiro-: «Assise au bord d'un grand trou rond, les jambes pendantes vers l'eau, qu'elle égratignait du bout de l'orteil, elle était nue». Ugolin sale de esta visión hechizado, loco de amor, convencido de haber visto a una diosa: «il sentait obscurément que cette dançante fille, encore fraîche de l'eau lustrale de la pluie, était la divinité des collines, de la pinède et du printemps» (Pagnol, 1972: II, 65-66).

También hay escena de bella durmiente en el texto de Pagnol y el mirón es de nuevo Ugolin: «[Manon] remonta vers la roche plate. Là, elle bourra sa musette d'herbe sèche, la plaça sur la pierre en guise d'oreiller, et s'endormit. Il la regarda longtemps, bouleversé par ce spectacle, à cause d'une vieille berceuse, qui parlait du "sommeil de l'innocence”» (Pagnol, 1972: II, 108-109). En cambio, la dormeuse cambiará de voyeur de la novela a la película de Berri: del campesino, que no la merece, al maestro y rival, que la desposará al final.

Como se ha comprobado, estos autores, pintores o dibujantes, novelistas o poetas, son reincidentes: no se limitan a proporcionar una sola escena, sino que vuelven reiteradamente sobre ella. Entre todos ilustran la evolución del motivo de la ninfa sorprendida en el sueño o en el baño. Los pintores convertirán esas deidades menores, espiadas -o no- por sátiros, en diosas, como Venus o Diana, para rebajarlas luego a cortesanas u odaliscas; mientras que los escritores harán de ellas pastoras, que se tornarán princesas o damas con la transformación de los géneros; y los sátiros serán sustituidos por pastores, príncipes o caballeros que dejan traslucir a menudo la lascivia de aquellos. Unas y otros recuperarán formas más simples cuando el arte -y, por ende, la literatura- vuelva a ocuparse de trasuntos más humanos. Así y todo, tanto el tratamiento formal de las manifestaciones plásticas como la estructura profunda de las recreaciones literarias ponen de relieve la persistencia de los mitos, siempre cambiantes y, al tiempo, imperecederos.

\section{Referencias bibliográficas}

Bataille, Georges (1957). L’Érotisme. París: Union Générale d’Éditions, col. 10/18.

Gonzalo SANTos, Tomás (1986). «La 'belle dormeuse’ de d’Urfé à Marivaux (recréations d'une scène érotique)», en Estudios Franceses, II, p. 149-156.

GonZalo Santos, Tomás (1987). «Jeanne de George Sand ou la tentation irrépressible de la pastorale», en Estudios Franceses, III, p. 103-113.

Gonzalo SAntos, Tomás (1991). «De pastores y ninfas, del mito de Hilas al mito de Céladon». En Dengler, Robert (ed.). Estudios humanísticos en homenaje a Luis Cortés Vázquez. Salamanca: Ediciones Universidad de Salamanca, p. 365-373.

GonZalo Santos, Tomás (2014). «El universo mítico de Marcel Pagnol: Jean de Florette y Manon des sources, en la versión cinematográfica de Claude Berri». En: Pardo, Pedro Javier y Sánchez Zapatero, Javier (eds.), Sobre la adaptación y más allá: trasvases filmoliterarios. Salamanca: Ediciones Universidad de Salamanca, p. 121-128.

GOYET, Francis (2012). «“La nymphe de la source” de Cranach l’Ancien : quelle nymphe ? quelle source?», en Transitions. Rúbrica:

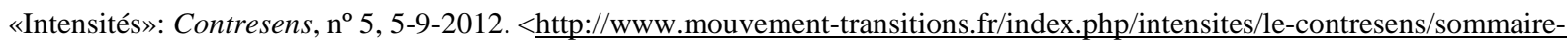
des-articles-deja-publies/526-qla-nymphe-de-la-sourceq-de-cranach-lancien> [Consultado el 14 de marzo de 2016].

La Calprenede, Gautier de Coste de (1752). Cassandre. París: Chez Bauche. Edición abreviada. 3 vols.

La CALPREnÈDE, Gautier de Coste de (1753). Faramond. París: Chez Bauche. Edición abreviada. 4 vols.

La FontAine, Jean de (1965). Les Amours de Psyché et de Cupidon en Euvres complètes. París: Seuil. 
La Fontaine, Jean de (1967). Le Songe de Vaux. Ginebra: Droz. Edición de E. Titcomb.

LARSON, Jennifer (2001). Greek Nymphs. Myth, Cult, Lore. Oxford: Oxford University Press.

LAVOCAT, Françoise (2005). La syrinx au bûcher: Pan et les satyres à la Renaissance et à l'âge baroque. Ginebra: Droz.

Leroux, Virginie (2011). «L’érotisme de la belle endormie», en Seizième Siècle, Vol. 7, nº 1, p. 15-35.

Marivaux, Pierre Carlet de Chamblain de (1972a). Les Aventures de *** ou Les Effets surprenants de la sympathie, en Euvres de jeunesse. París: Gallimard, col. «La Pléïade». Edición de Frédéric Deloffre.

Marivaux, Pierre Carlet de Chamblain de (1972b). Pharsamon ou les Nouvelles Folies romanesques, en Euvres de jeunesse. París: Gallimard, col. «La Pléïade». Edición de Frédéric Deloffre.

MARSAn, Jules (1969). La Pastorale dramatique en France à la fin du XVIe et au commencement du XVIIe siècle. Ginebra: Slatkine Reprints; reimpr. de la edición de París, 1905.

Molina FoIX, Juan Antonio (ed.) (2005). Ondinas: las ninfas del agua. Madrid: Siruela.

Pagnol, Marcel (1971-1972). L’Eau des collines. I: Jean de Florette. II: Manon des sources [1960]. París: Le Livre de poche, 2 vols.

Regueras Grande, Fernando et al. (1994). Rapto y rescate del héroe. El Mosaico de «Hilas y las ninfas». Museo de León. [Valladolid]: Junta de Castilla y León-Consejería de Cultura y Turismo.

Ruiz De Elvira, Antonio (1999). «Ninfa de la fuente», en Cuadernos de Filología Clásica. Estudios Latinos, n 17, p. 177-180.

SAND, George (1978). Jeanne. Grenoble: Presses Universitaires de Grenoble. Edición de Simone Vierne.

TEÓCRITO (1986). Idilios. En: Bucólicos griegos. Madrid: Gredos, p. 35-54.

URFE, Honoré d’ (1966). L’Astrée. Ginebra: Slatkine Reprints. Reimpresión de la edición de Lyon, 1925-1928. 5 vols.

YourCENAR, Marguerite (1982). L’homme qui a aimé les Néréides, en Nouvelles Orientales. París: Gallimard, col. L’imaginaire, p. 79-88. 